\title{
Kahweol induces apoptosis by suppressing BTF3 expression through the ERK signaling pathway in non-small cell lung cancer cells
}

\author{
YOUNG-JOO JEON ${ }^{1,2^{*}}$, WOONG BANG ${ }^{1 *}$, JIN HYOUNG CHO ${ }^{1}$, RA HAM LEE ${ }^{1}$, SEOK-HO KIM $^{3}$, \\ MINSEOK S. KIM ${ }^{4}$, SEON-MIN PARK ${ }^{5}$, JAE-CHEON SHIN ${ }^{5}$, HAK-JAE CHUNG ${ }^{6}$, KEON BONG OH ${ }^{6}$, \\ JAE-MIN SEO $^{7}$, SUNGHO KO ${ }^{8}$, JUNG-HYUN SHIM ${ }^{9,10}$ and JUNG-IL CHAE ${ }^{1}$
}

\author{
${ }^{1}$ Department of Dental Pharmacology, School of Dentistry, BK21 Plus, Chonbuk National University, Jeonju, Jeolla 561-756; \\ ${ }^{2}$ National Marine Biodiversity Institute of Korea, Seocheon, Chungcheong 33662; ${ }^{3}$ Aging Research Institute, \\ Korea Research Institute of Bioscience and Biotechnology, Yuseong, Daejeon; ${ }^{4}$ Department of Biomedical Engineering, \\ Konyang University, Seo, Daejeon; ${ }^{5}$ Pohang Center for Evaluation of Biomaterials, Pohang, Gyeongsang 790-834; \\ ${ }^{6}$ Animal Biotechnology Division, National Institute of Animal Science, Rural Development Administration, \\ Suwon, Gyeonggi; ${ }^{7}$ Cluster for Craniofacial Development and Regeneration Research, Institute of Oral Biosciences \\ and School of Dentistry, Chonbuk National University, Jeonju, Jeolla; ${ }^{8}$ Department of Applied Bioscience, \\ CHA University, Seongnam, Gyeonggi 463-836; ${ }^{9}$ Department of Pharmacy, College of Pharmacy and \\ Natural Medicine Research Institute, Mokpo National University, Mokpo, Jeolla 534-729, \\ Republic of Korea; ${ }^{10}$ The China-US (Henan) Hormel Cancer Institute, Zhengzhou, Henan, P.R. China
}

Received June 15, 2016; Accepted August 4, 2016

DOI: $10.3892 /$ ijo.2016.3727

\begin{abstract}
Kahweol, a diterpene molecule, has antiproliferative effects on several types of human cancer cells, but whether it has apoptotic effect in non-small cell lung cancer (NSCLC) is not known. To explore this possibility, we incubated cells from two NSCLC cell lines, NCI-H358 and NCI-H1299, with different concentrations of kahweol and used the MTS assay, DAPI staining, propidium iodide staining, Annexin V staining, immunocytochemical test, and western blot analysis to characterize this molecule and the signaling pathway underlying its effects. The kahweol-treated cells showed significantly decreased cell viability, increased nuclear condensation, and an increased number of Annexin V-positive NSCLC cells.
\end{abstract}

Correspondence to: Professor Jung-Hyun Shim, Department of Pharmacy, College of Pharmacy and Natural Medicine Research Institute, Mokpo National University, Mokpo, Jeolla 534-729, Republic of Korea

E-mail: s1004jh@gmail.com

Professor Jung-Il Chae, Department of Dental Pharmacology, School of Dentistry, BK21 Plus, Chonbuk National University, Jeonju, Jeolla 561-756, Republic of Korea

E-mail: jichae@jbnu.ac.kr

${ }^{*}$ Contributed equally

Key words: kahweol, non-small cell lung cancer, basic transcription factor 3, ERK, apoptosis
Suppression of basic transcription factor 3 (BTF3) was followed by apoptosis induced by kahweol via the ERK-mediated signaling pathway in a dose- and time-dependent manner. In addition, kahweol modulated the protein expression of BTF3 genes involved in cell-cycle regulation and apoptosis-related proteins, resulting in apoptotic cell death. Our results collectively indicated that kahweol inhibited the proliferation of NSCLC cells through ERK-mediated signaling pathways and the downregulation of BTF3.

\section{Introduction}

Lung cancer is the most frequent cause of cancer-related deaths worldwide, with mortality estimated to exceed 1 million deaths each year (1). An estimated 224,210 new cases of lung and bronchial cancers were diagnosed in 2014, and 159,260 deaths are estimated to occur from the disease (2). Non-small cell lung cancer (NSCLC) accounts for almost $85 \%$ of all cases of lung cancer and comprises mainly adenocarcinoma, squamous cell carcinoma, and large-cell carcinoma (3). The most important risk factor for NSCLC is cigarette smoking, followed by occupational and environmental exposures (4). Although the predominant treatment for NSCLC still involves a combination of surgery, radiation therapy, and chemotherapy, some patients have conditions that make them ineligible for surgical treatment (5). Thus, the discovery and development of an effective chemotherapeutic agent might improve survival rates for patients with NSCLC.

Coffee beans contain more than a thousand compounds, one of which is kahweol (6). Kahweol, a diterpene molecule (Fig. 1A), is present in oil derived from Arabica coffee beans 
(7) and has been shown to have a wide variety of biological activities, including anti-angiogenic and anti-inflammatory effect in HUVEC, antitumor effect on human breast cancer, antiproliferative properties in oral squamous cancer, suppression of iNOS and cyclooxygenase in RAW 264.7 cell and chemoprotective and antitumorigenic effect in organs of rat (8-14). However, in NSCLC, the anti-apoptotic mechanisms and molecular targets of kahweol are poorly understood.

Basic transcription factor 3 (BTF3), a general RNA polymerase II transcription factor, acts as a modulator of apoptosis and is differentially expressed in several types of cancer (15). The biological important role of BTF3 was shown in mouse embryos, homozygous for loss of function mutation in the BTF3 gene, that died at the early stage of development (16) and changes in BTF3 expression have been shown to be related to apoptosis in the BL60-2 Burkitt lymphoma cell line (17). In several cancer cell lines, BTF3 is overexpressed (18-20) but as an apoptosis-related protein, its pattern of expression in NSCLC is still unknown.

The use of chemotherapy in patients with advanced NSCLC requires further investigation. Therefore, we investigated the potential regulatory effect of kahweol on viability and apoptosis of the NSCLC cell lines NCI-H358 and NCI-H1299, and its anti-apoptotic mechanism in relation to BTF3.

\section{Materials and methods}

Reagent and antibodies. Kahweol was purchased from Santa Cruz Biotechnology (Dallas, TX, USA). The MEK1 inhibitor PD98059 was purchased from Sigma-Aldrich (St. Louis, MO, USA). Antibodies, including BTF3, PARP, caspase-3, Bcl-2, Bcl-xl, Bax, p27, p21, cyclin D1, survivin, and $\beta$-actin, were obtained from Santa Cruz Biotechnology (Paso Robles, CA, USA). Anti-ERK and anti-phospho-ERK antibodies were purchased from Cell Signaling Technology (Danvers, MA, USA).

Cell lines and culture conditions. NCI-H358 (ATCC CRL-5807) and NCI-H1299 (ATCC CRL-5803) were obtained from the American Type Culture Collection (ATCC). NCI-H358 was derived from tumor tissue obtained from a patient prior to initiation of chemotherapy and NCI-H1299 was established from a lymph node metastasis of the lung from a patient who had received prior radiation therapy (Manassas, VA, USA). These NSCLC lines were grown routinely in RPMI-1640 medium (Welgene, Deagu, Korea) with 10\% fetal bovine serum (FBS) and $100 \mathrm{U}$ each of penicillin and streptomycin (Gibco, Grand Island, NY, USA) at $37^{\circ} \mathrm{C}$ with $\mathrm{CO}_{2}$ in a humidified atmosphere.

Cell viability assay. We performed the MTS assay (3-(4,5-dimethylthiazol-2-yl)-5-(3-carboxymethoxyphenyl)2-(4-sulfophenyl)-2H-tetrazolium) to assess cell viability. NCI-H358 cells $\left(2.5 \times 10^{3}\right)$ and NCI-H1299 cells $\left(2.5 \times 10^{3}\right)$ were seeded in 96-well plates and were incubated overnight. The cells were treated with different concentrations of kahweol [0 (control), 30, 60 and $90 \mu \mathrm{M}$ ] and then incubated for 24 and $48 \mathrm{~h}$. Absorbance was measured at $490 \mathrm{~nm}$ using a BioTek Microplate Reader (BioTek, Winooski, VT, USA). The percentages of viable kahweol-treated cells were normalized to those of untreated cells.

DAPI staining. Apoptosis of kahweol-treated cells, nuclear condensation, and fragmentation were detected by means of 4'-6-diamidino-2-phenylindole (DAPI) staining. NCI-H358 and NCI-H1299 cells were treated with different concentrations of kahweol for $48 \mathrm{~h}$. The cells were harvested by trypsinization and were then fixed in $100 \%$ methanol at room temperature for $30 \mathrm{~min}$ and washed with phosphate-buffered saline (PBS). The washed cells were stained with DAPI solution (Sigma-Aldrich) $(2 \mu \mathrm{g} / \mathrm{ml})$ for $20 \mathrm{~min}$ in the dark, and the stained cells were imaged by confocal microscopy using a Nikon C2 Plus System (Nikon Corp., Tokyo, Japan).

Immunocytochemical testing. Glass coverslips were sterilized on 6-well tissue culture plates, and the NCI-H358 and NCI-H1299 cells were seeded for $24 \mathrm{~h}$. After being treated with different concentrations of kahweol for $48 \mathrm{~h}$, the cells were fixed and permeabilized with Cytofix/Cytoperm solution (BD Biosciences, San Jose, CA, USA) for $30 \mathrm{~min}$ at $4^{\circ} \mathrm{C}$. The cells were incubated with monoclonal BTF3 antibody containing $1 \%$ bovine serum albumin (BSA) at $4^{\circ} \mathrm{C}$ overnight in the dark and then washed with PBS. The BTF3 antibody was reacted with Alexa Fluor 546-conjugated anti-mouse IgG at room temperature for $1 \mathrm{~h}$ in the dark. The reacted cells were washed with PBS-T and were stained with DAPI solution (Sigma-Aldrich) $(2 \mu \mathrm{g} / \mathrm{ml})$ for $20 \mathrm{~min}$ in the dark. The stained cells were observed under the FluoView confocal laser scanning microscope.

Annexin V assay and PI staining. Apoptosis can be evaluated by means of simultaneous staining with Annexin V-FITC and propidium iodide (PI). Annexin V-FITC staining reveals the early stage of apoptosis, and PI staining shows the late stage. The NCI-H358 and NCI-H1299 cells were incubated with various concentrations of kahweol for $48 \mathrm{~h}$, after which the cells were harvested using a scraper. The harvested cells were stained with Annexin V-FITC and PI and then assessed by means of fluorescence-activated cell sorting (FACS) (BD Biosciences).

Western blot analysis. The kahweol-treated NCI-H358 and NCI-H1299 cells were cultured for 48 h, washed with cold PBS, and then lysed using M-PER Mammalian Protein Extraction Reagent (Thermo Scientific, Rockford, IL, USA) that contained a protease inhibitor cocktail (Roche, Basel, Switzerland). The protein concentration was measured using the BCA Protein Assay kit (Thermo Scientific). Samples were separated on SDS-polyacrylamide gels and transferred to polyvinylidene difluoride membranes (Millipore, Billerica, MA, USA). The membranes were blocked with $5 \%$ skim milk in Tris-buffered saline (TBS) with $0.1 \%$ Tween-20 for 20-30 min at room temperature and were incubated with the primary antibodies at $4^{\circ} \mathrm{C}$ overnight. Subsequently, the membranes were washed five times in TBS buffer with $0.1 \%$ Tween-20 for $10 \mathrm{~min}$ and rotated for $1 \mathrm{~h}$ at room temperature in a solution of horseradish peroxidase-conjugated anti-mouse, anti-rabbit, or anti-goat IgG antibodies. The membranes were developed using a chemiluminescent ECL Detection kit (Thermo 

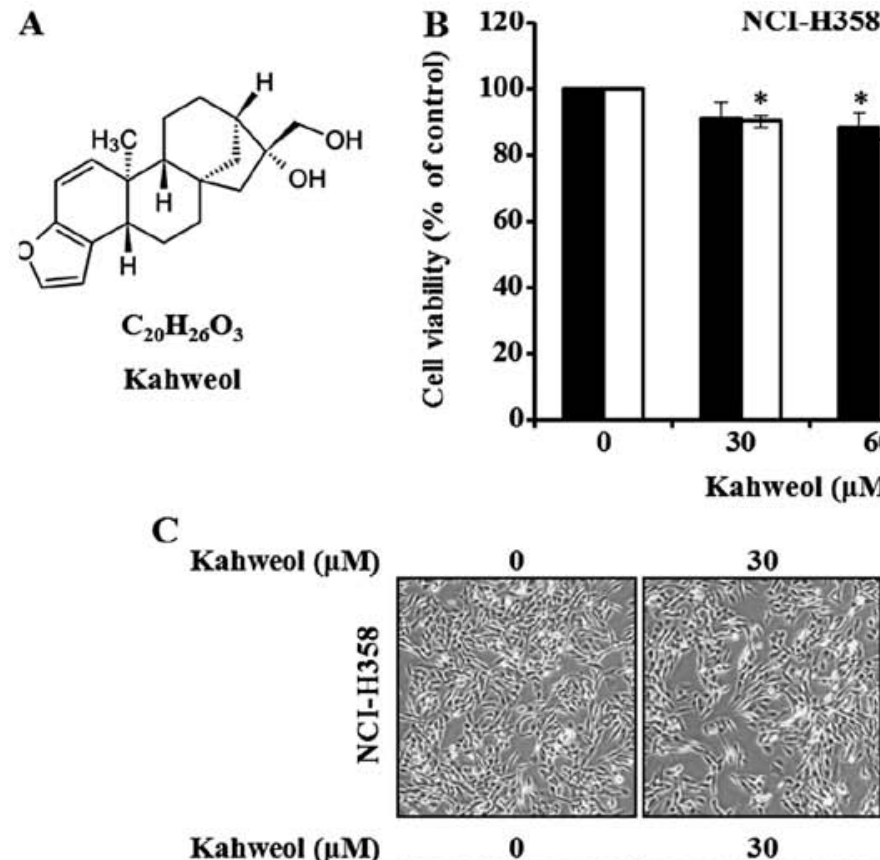

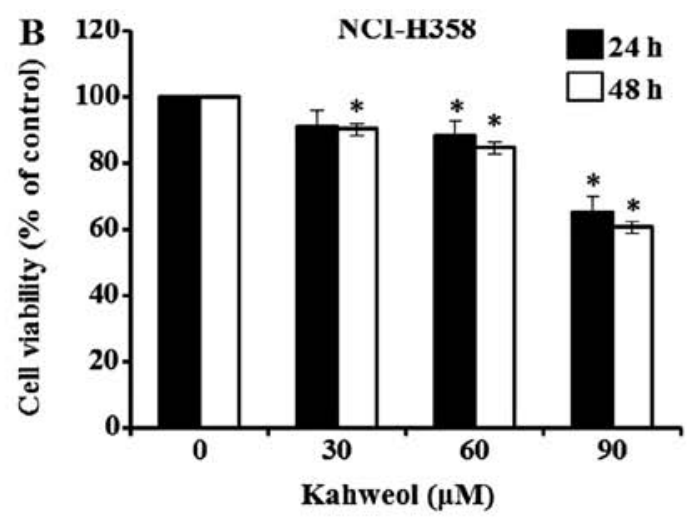

60
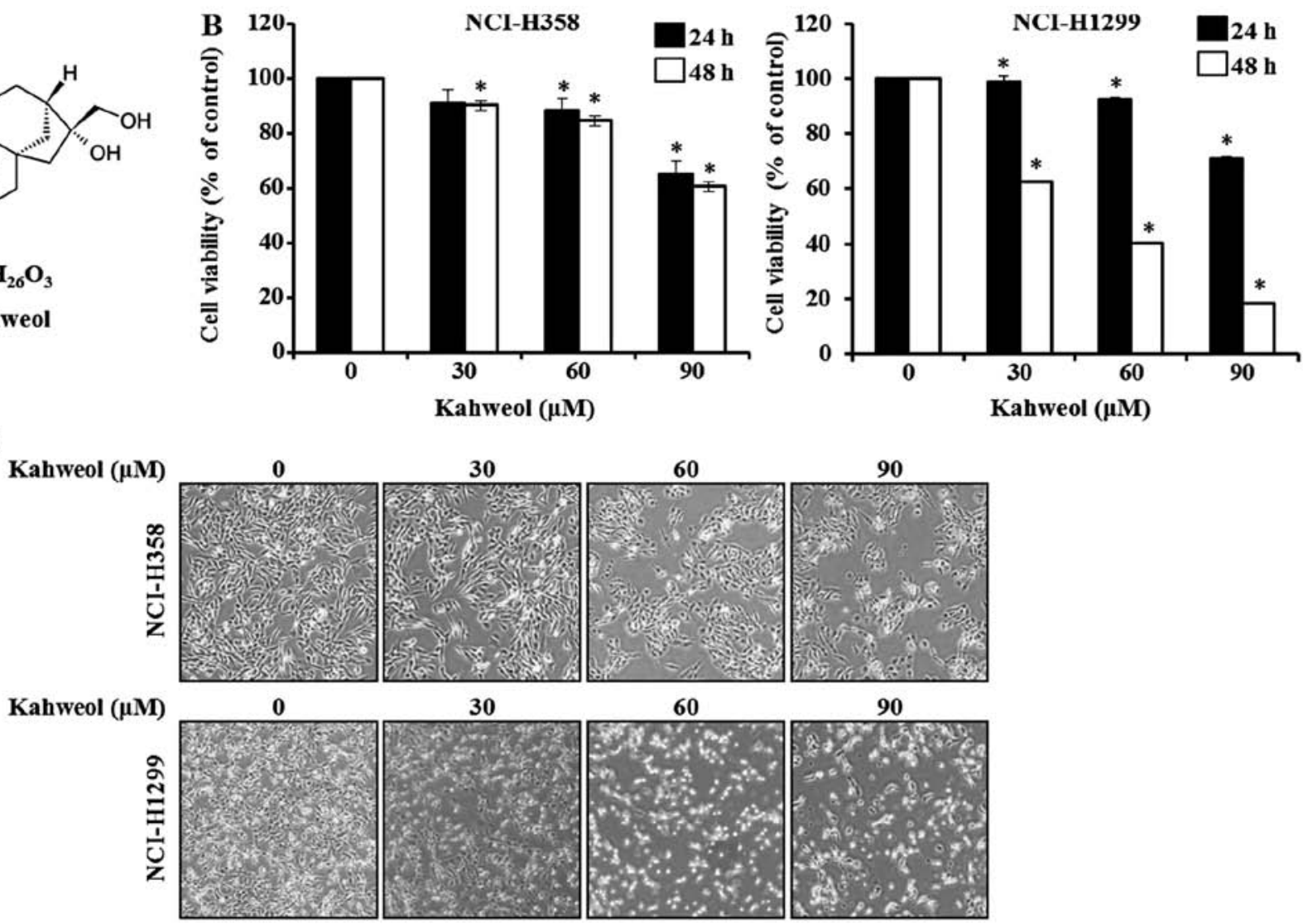

Figure 1. Effect of kahweol on cell viability of NSCLC cell lines. (A) Chemical structure of kahweol. (B) The effect of kahweol on the viability of NCI-H358 and NCI-H1299 cells. The cells were seeded, $2.5 \times 10^{3}$ cells/well, into 96 -well plates and incubated for 24 and $48 \mathrm{~h}$ without or with kahweol (30, 60 and $\left.90 \mu \mathrm{M}\right)$. Cell viability was measured using the MTS assay (Materials and methods). Values represent means \pm SD for three independent experiments ( ${ }^{*}<0.05$ ). (C) Morphological alterations in the NCI-H358 and NCI-H1299 cells were noted after treatment with 30,60 and $90 \mu \mathrm{M}$ of kahweol for 48 h.

Scientific) and detected using ImageQuant LAS 4000 Mini software (GE Healthcare Life Sciences, Buckinghamshire, UK) according to the manufacturer's instructions.

Statistical analysis. Data are presented as means \pm SD from three independent experiments. Data analysis for statistical significance were obtained with use of Student's t-test. As compared with the vehicle control, p-values $<0.05$ indicated statistical significance.

\section{Results}

Growth inhibitory effect of kahweol on NSCLC cells. We investigated whether kahweol could effectively suppress the cell proliferative capability of the two NSCLC cell lines NCI-H358 and NCI-H1299. To determine cell viability, we treated the cells with different concentrations of kahweol (30, 60 and $90 \mu \mathrm{M})$ at different time-points (24 or $48 \mathrm{~h})$. Cell viability was calculated $48 \mathrm{~h}$ after treatment using the MTS assay (Fig. 1B). The values for NCI-H358 were 90.1 \pm 0.02 , $84.6 \pm 0.02$ and $60.6 \pm 0.05 \%$ at kahweol concentrations of 30,60 and $90 \mu \mathrm{M}$, respectively; the corresponding values for NCI-H1299 were $62.5 \pm 0.01,40.4 \pm 0.01$ and $18.4 \pm 0.01 \%$, respectively, as compared with the untreated control cells. On microscopy, we observed morphological changes in the cells in the kahweol-containing medium that reflected apoptosis. As shown in Fig. 1C, the apoptotic phenotype at $48 \mathrm{~h}$ included cell rounding, cytoplasmic blebbing, and irregularities in shape. In light of inhibition of cell viability by treating kahweol in a dose- and time- dependent manner, kahweol treatment affected the cell viability decrease.

Kahweol induces apoptosis in NSCLC cells. Cytoplasmic blebbing and morphological irregularities are critical hallmarks of apoptosis (21). We examined the nuclear integrity of the NSCLC cells treated with kahweol to determine whether this compound would induce apoptosis. To detect any apoptotic changes in the kahweol-treated NCI-H358 and NCI-H1299 cells, we used DAPI staining and then viewed the cells using a confocal laser scanning microscope. The percentage of cells with nuclear condensation in the kahweoltreated group versus the DMSO-treated group is shown in Fig. 2A. Using an Annexin V assay, we verified the presence of kahweol-mediated apoptosis and found that the ratio of early-to-late apoptotic cells was significantly increased in the kahweol-treated NCI-H358 and NCI-H1299 cells relative to the untreated control cells (Fig. 2B). These results indicate that apoptosis of NSCLS cell lines result from increase of apoptotic changes and nuclear condensation by treating kahweol.

Kahweol suppresses BTF3 expression levels in NSCLC cell lines. The transcription factor BTF3 has been shown to cause significant proliferation of several cancer cell lines (18-20) indicating that it critically influences cell cycle arrest and 
$\mathbf{A}$

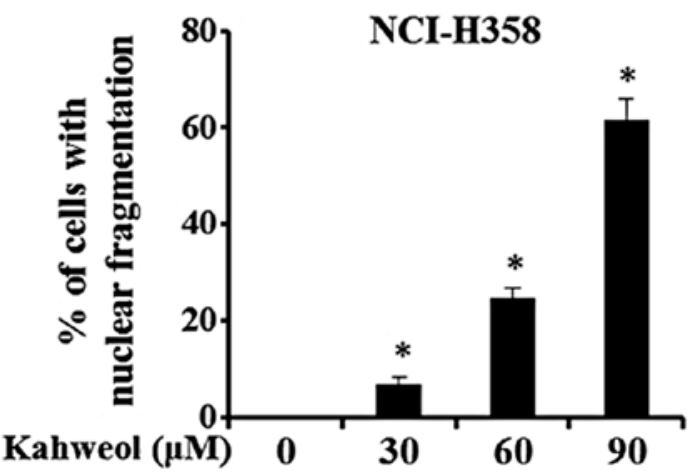

B

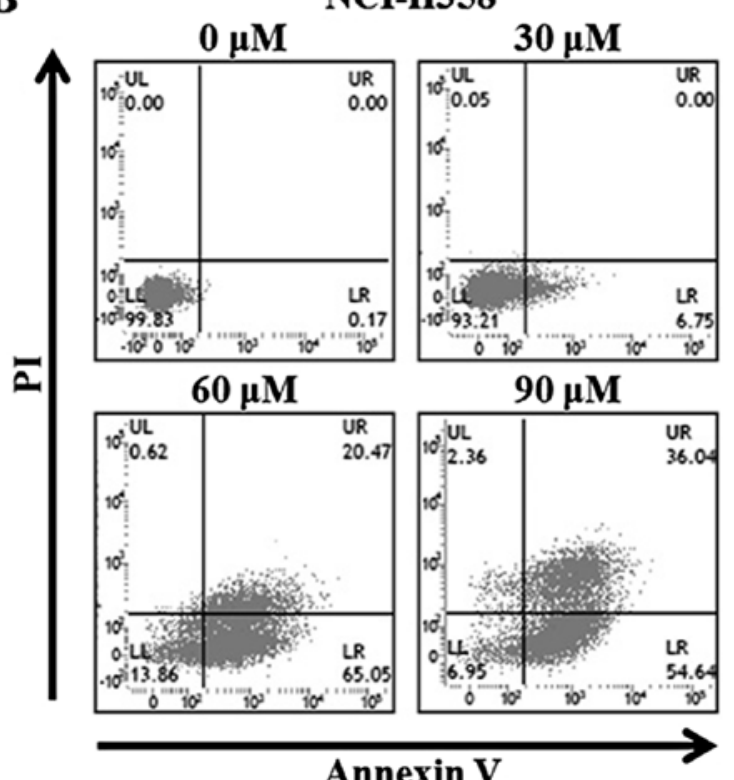

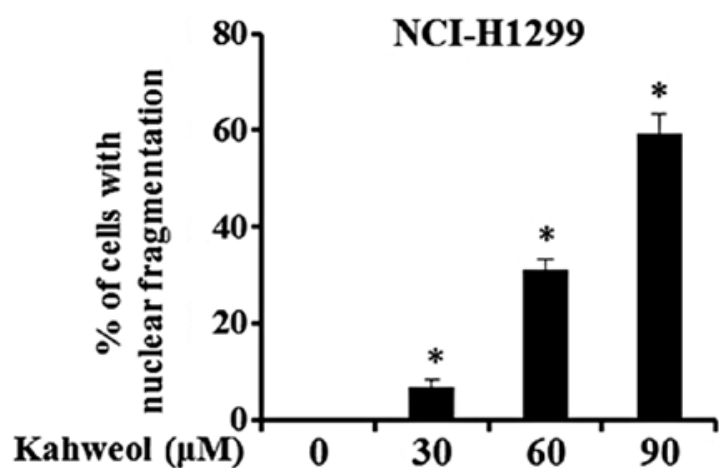

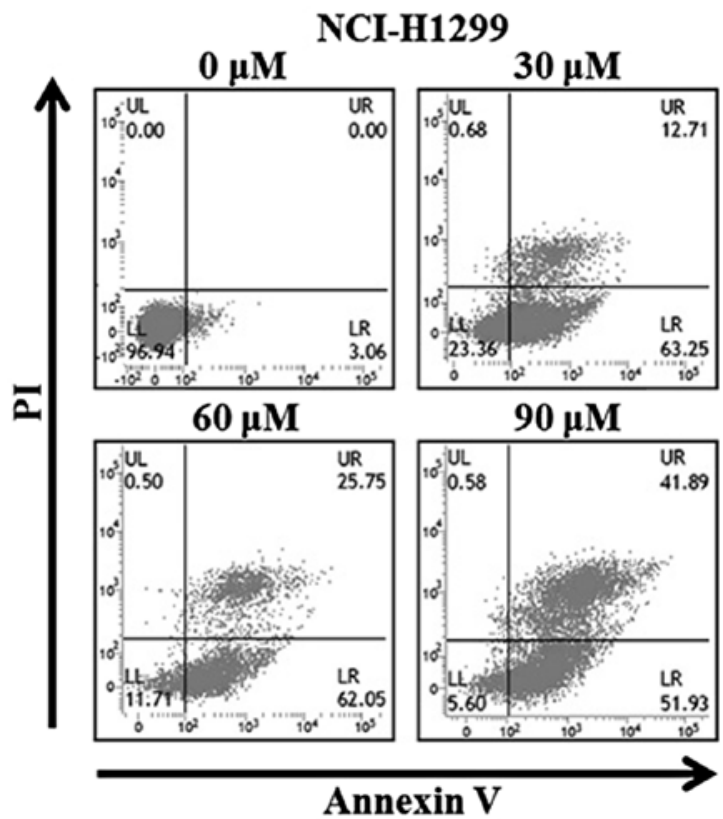

Figure 2. Apoptotic effect is induced by kahweol in NSCLC cell lines. (A) NCI-H358 and NCI-H1299 cells treated with kahweol (0, 30,60 and $90 \mu \mathrm{M})$ were detected using DAPI staining (Materials and methods). The cells that exhibited DNA fragmentation and chromatin condensation were quantified, and the values are represented on a graph. Values are means \pm SD for three replicate experiments ( $*$ p $<0.05$ ). (B) NCI-H358 and NCI-H1299 cells were treated with kahweol, and apoptosis was analyzed via Annexin V-FITC and PI staining. The results are plotted on a dot graph. Values shown represent the average of triplicate samples from independent experiments.

apoptosis $(17,22,23)$. If the level of BTF3 expression could be effectively modulated by a chemotherapeutic agent, that agent might be useful in anticancer therapy. To determine whether BTF3-mediated apoptosis of NSCLC cells might be induced by treatment with kahweol, we used western blot analysis to examine NSCLC cells treated for $48 \mathrm{~h}$ with different concentrations of kahweol $(30,60$ and $90 \mu \mathrm{M})$. Indeed, this treatment induced a marked decrease in the expression levels of BTF3 in the NCI-H358 and NCI-H1299 cells in a dosedependent manner (Fig. 3A and B). To further investigate the apoptotic effects of BTF3 downregulation, we examined the cells at $0,12,24$, and $48 \mathrm{~h}$. BTF3 expression levels decreased significantly as time progressed. Kahweol also induced the cleavage of poly-(ADP-ribose) polymerase (PARP), resulting in apoptosis (Fig. 3C and D). Immunocytochemical testing was used to confirm these results. The levels of BTF3 expression were reduced in the kahweol-treated NSCLC cells in a dose-dependent manner (Fig. 3E). Collectively, these data indicate that in light of BTF3 expression decrease by treatment with kahweol, downregulation of BTF3 by kahweol leads to apoptotic cell death.

Kahweol induces inactivation of the ERK signaling pathway in NSCLC cells. The ERK pathway plays an important role in cell proliferation (24) and can be activated by various stimuli, including chemotherapeutic agents (25). We performed western blot analysis to investigate the role of ERK pathways in the kahweol-induced reduction of BTF3 expression levels. Although the expression levels of extracellular signalregulated kinase 1 and 2 (ERK1/2) were not changed, the level of phospho-ERK1/2 expression was decreased by various concentration of kahweol (Fig. 4A and B). Furthermore, in order to investigate whether BTF3 is a target of the ERK signaling pathway, we applied PD98059, an ERK-specific inhibitor. When the NSCLC cells were exposed to kahweol or PD98059, the phosphorylation of ERK was significantly suppressed (Fig. 4C and D). In addition, when the cells were treated with kahweol plus PD98059, definite suppressive effect 
A

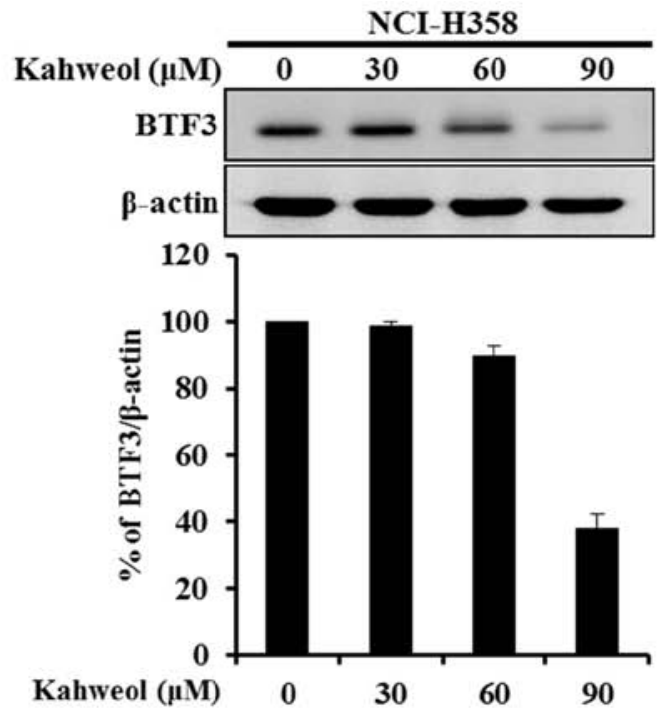

C

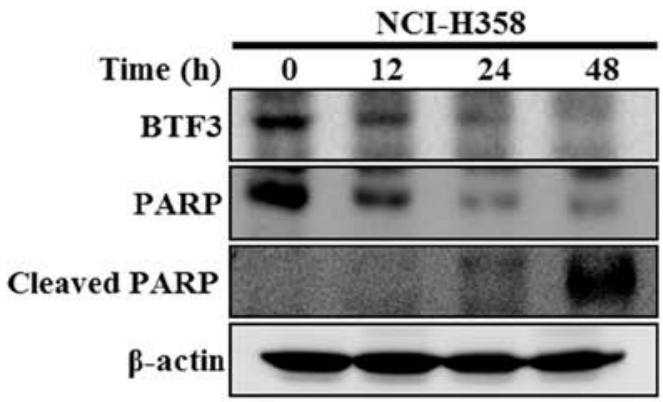

B

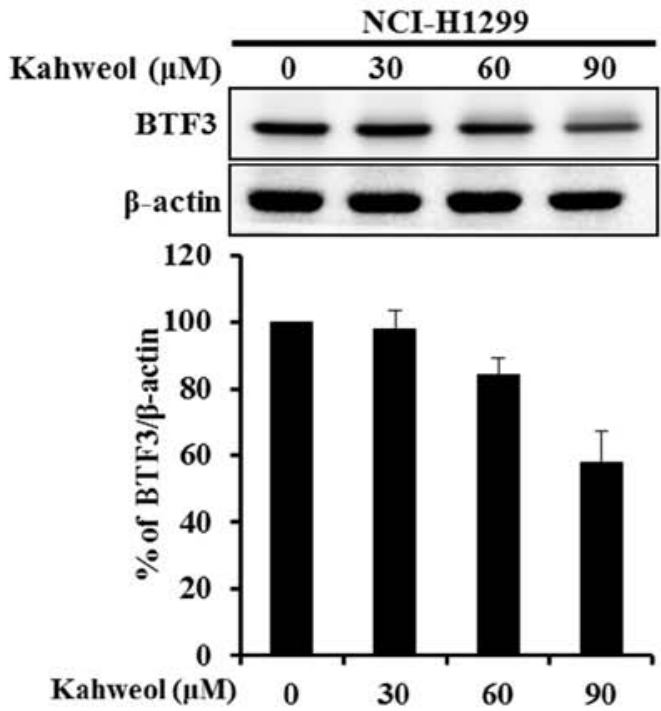

D

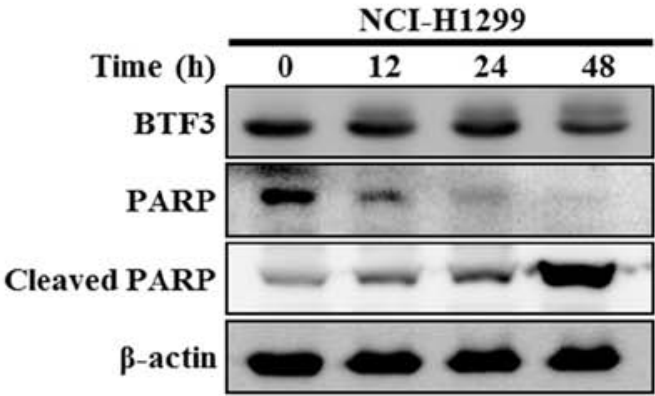

$\mathbf{E}$
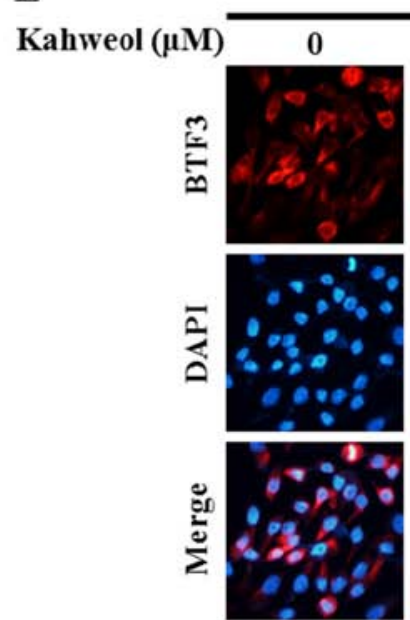

NCI-H358
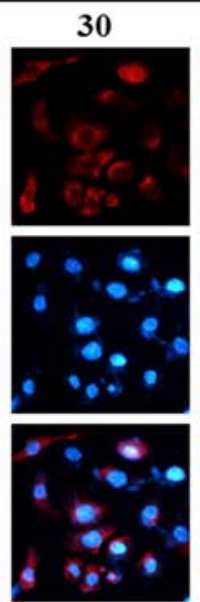

60
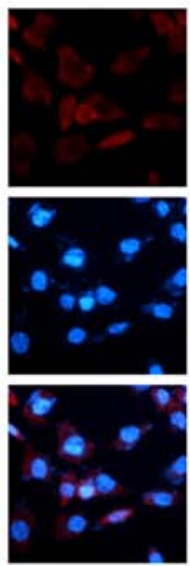
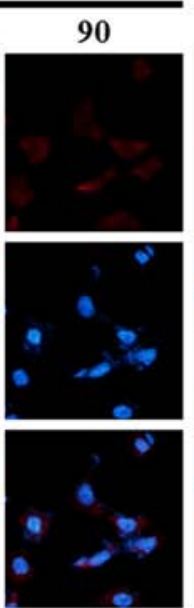

NCI-H1299
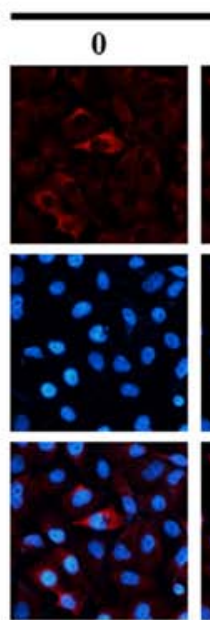

60

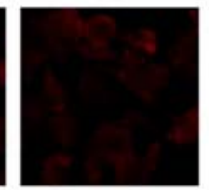

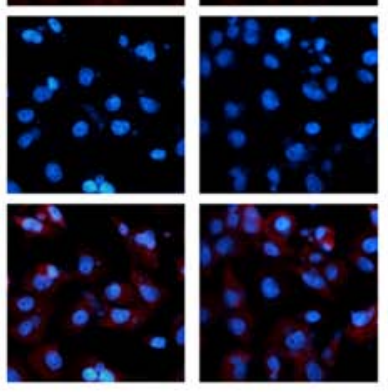

$20 \mu \mathrm{m}$

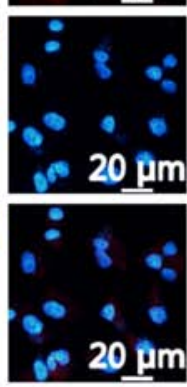

Figure 3. Effect of kahweol on the expression of BTF3 in the NSCLC cell lines. NCI-H358 and NCI-H1299 cells were incubated with various concentrations of kahweol $(0,30,60$ and $90 \mu \mathrm{M})$ for $48 \mathrm{~h}$ and were then harvested and prepared for western blot analysis (Materials and methods). BTF3 expression levels in the NCI-H358 cells (A) and the NCI-H1299 cells (B) were detected by means of a specific antibody against BTF3, and the graphs indicate the ratio of BTF3 to $\beta$-actin expression. Equal protein loading was confirmed using $\beta$-actin. NCI-H358 cells (C) and NCI-H1299 cells (D) treated with the $90 \mu$ M concentration of kahweol were incubated for different periods of time, and the expression levels of BTF3 were measured using western blot analysis. Equal protein loading was confirmed using $\beta$-actin. (E) Immunocytochemical analysis of the NCI-H358 and NCI-H1299 cells treated for 48 h with kahweol. The cells were immunostained with BTF3 antibody, and the BTF3 signals were detected using Alexa Fluor 546-conjugated anti-mouse secondary antibody. The nucleus was stained with DAPI staining.

was observed. These results indicate that BTF3 was regulated by inhibiting the ERK signaling pathway through the effect of kahweol similar to PD98059 in NSCLC cells.

Kahweol regulates the arrest of cell cycle proteins and apoptosis-regulating proteins in NSCLC cells. Next, we examined whether kahweol treatment regulated the expression levels of various proteins related to cell cycle arrest and apoptosis. The levels of cell cycle arrest-related proteins, including p27 and $\mathrm{p} 21$, were increased, whereas the levels of proteins related to cell proliferation and survival, including cyclin D1 and survivin, were decreased (Fig. 5A and B). Moreover, when 
A

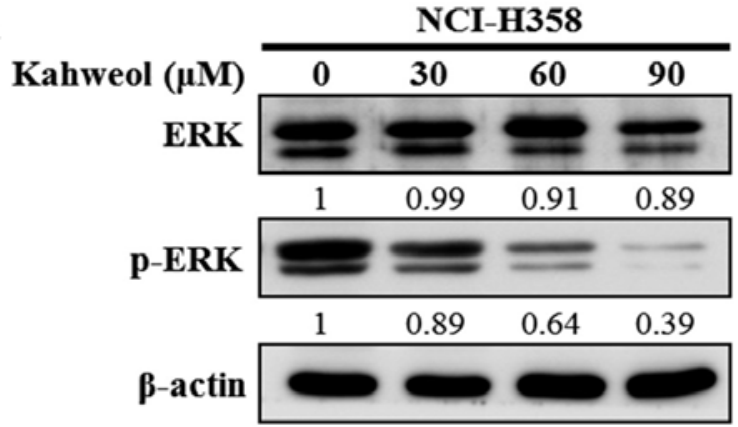

C

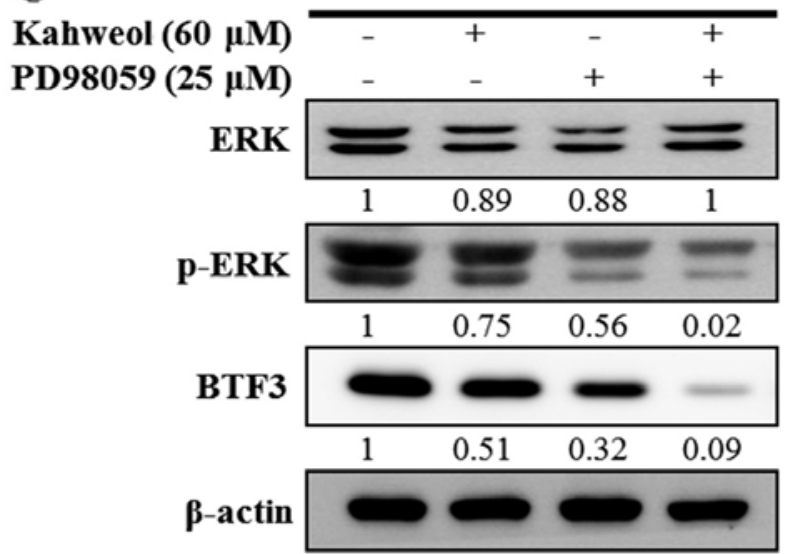

B

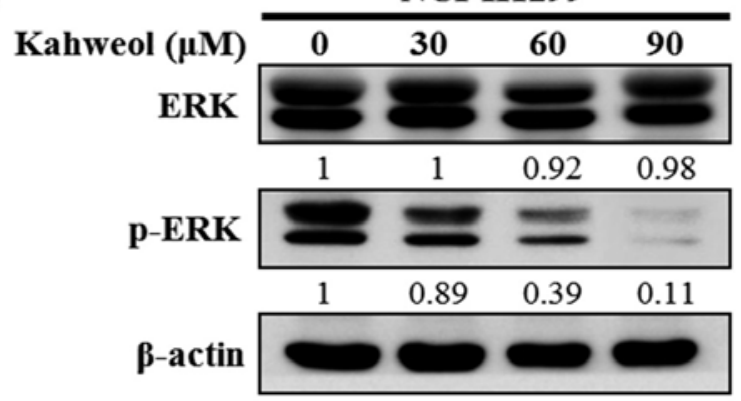

D

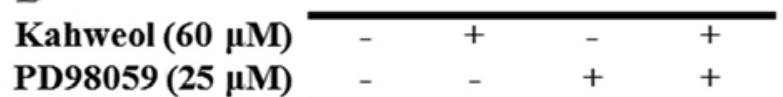

PD98059 (25 $\mu \mathrm{M})$

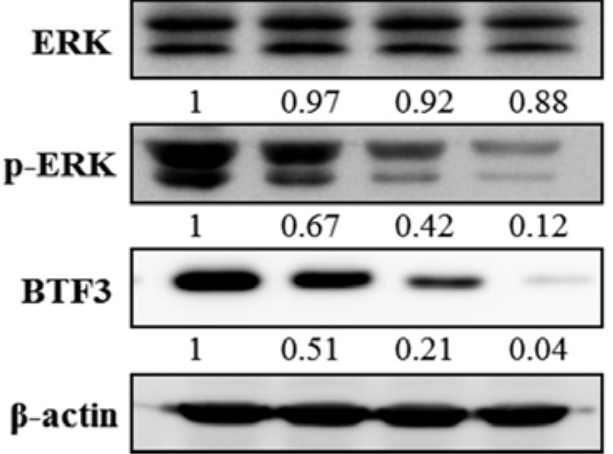

Figure 4. Inactivation of the ERK signaling pathway by kahweol in NSCLC cell lines. The NCI-H358 cells (A) and the NCI-H1299 cells (B) were incubated with kahweol $(0,30,60$ and $90 \mu \mathrm{M})$ for $48 \mathrm{~h}$, and the expression levels of ERK and p-ERK were assayed with western blotting using antibodies against ERK and p-ERK. NCI-H358 cells (C) and NCI-H1299 cells (D) were treated with kahweol (60 $\mu \mathrm{M})$ and ERK inhibitor (PD98059). $\beta$-actin represents the loading control.

A

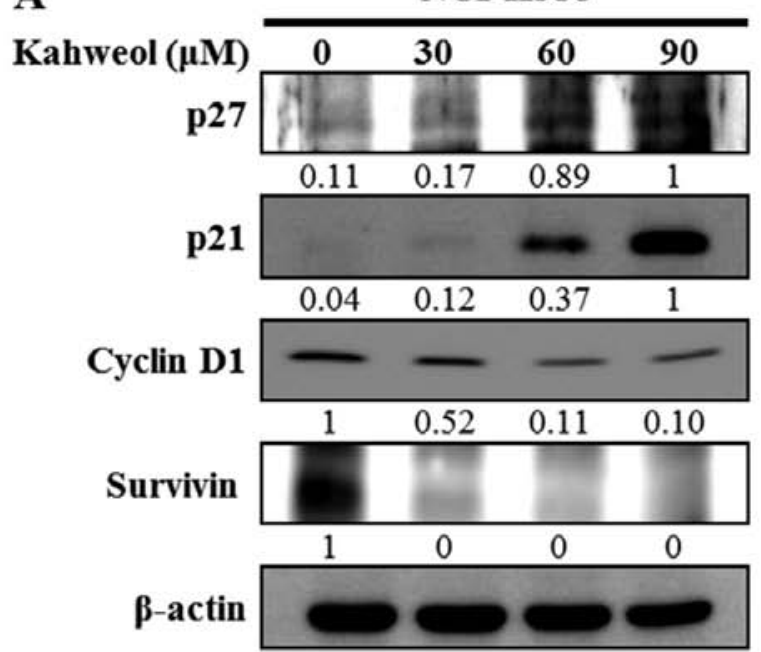

B

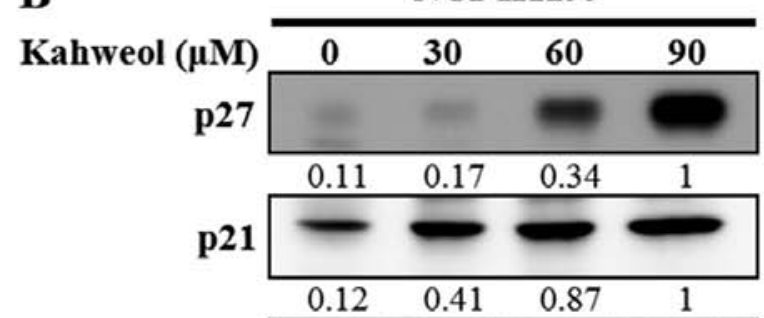

Cyclin D1

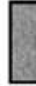

NCI-H1299

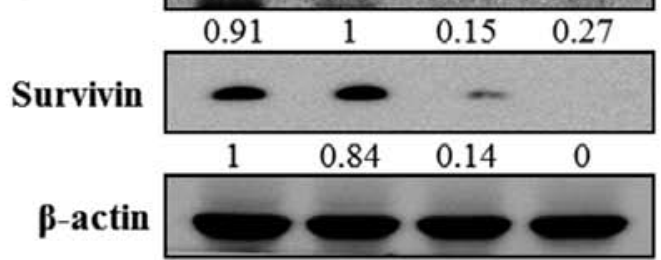

Figure 5. Effect of kahweol on downstream target proteins of downregulated BTF3. NCI-H358 cells (A) and NCI-H1299 cells (B) were treated with various concentrations of kahweol and the cell lysates were measured using western blot analysis with antibodies against p27, p21, cyclin D1, and survivin. Equal protein loading was confirmed using $\beta$-actin. Values were measured by means of ImageJ densitometry (National Institutes of Health, Bethesda, MD, USA) and represent the results of two or three independent experiments.

we tested pro-apoptotic and anti-apoptotic protein levels at different doses of kahweol, caspase-3 and PARP were activated in a dose-dependent manner. In addition, the downregulation of Bcl-2 and Bcl-xl and the upregulation of Bax appeared to be 

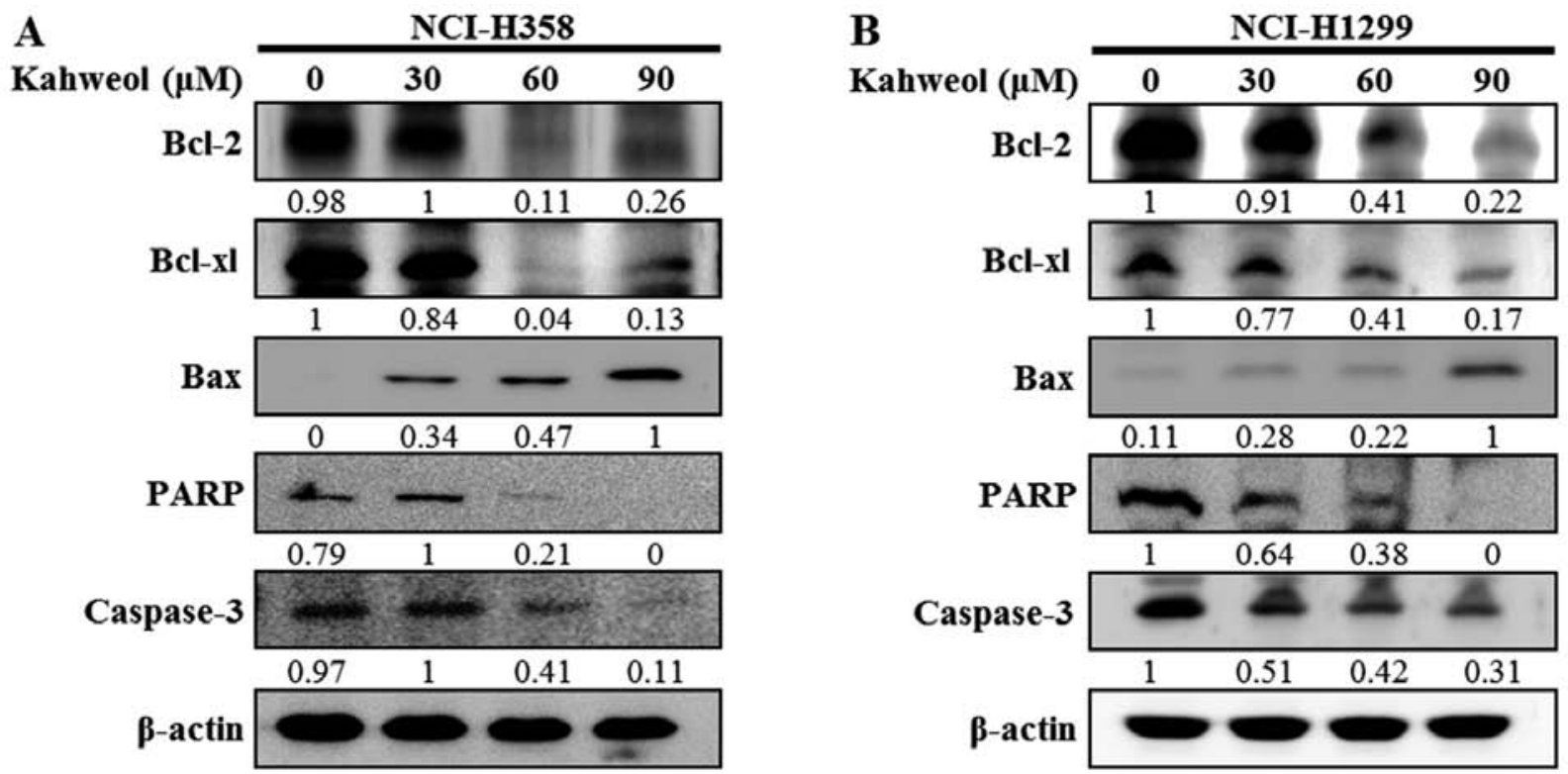

Figure 6. Effect of kahweol on apoptotic cell death in the NSCLC cell lines. NCI-H358 cells (A) and NCI-H1299 cells (B) treated with kahweol were incubated for $48 \mathrm{~h}$ and then harvested. The cell lysates were separated with SDS-PAGE gels, and the gels were transferred to PVDF membranes. The membranes were detected using antibodies against Bcl-2, Bcl-xl, Bax, PARP, and caspase-3. Equal protein loading was confirmed using $\beta$-actin. Values were measured by means of ImageJ densitometry and represent the results of two or three independent experiments.

involved in apoptotic cell death induced by kahweol (Fig. 6A and B). These results suggest that kahweol-induced cytotoxicity regulates BTF3 through inhibition of the ERK signaling pathway and leads to both cell cycle arrest and apoptotic cell death.

\section{Discussion}

Coffee contains numerous antioxidants and phenolic compounds, some of which have antitumor effects in various cancers (26). One of the bioactive compounds associated with the antitumor effects of coffee is kahweol $(7,27,28)$. Kahweol has been shown to have anti-inflammatory, anticarcinogenic, and antitumor effects $(8,9,12-14)$. Moreover, several animal studies showed that kahweol increased blood cholesterol and was compatible with a chemoprotective activity against various toxicants and procarcinogens (29-33). Although studies of kahweol-induced apoptosis have been carried out involving many cancer cell lines, its antiproliferative mechanisms in human NSCLC cells remained to be investigated. We therefore treated NSCLC cells with different concentrations of kahweol and conducted various analyses to determine the potential effects of this compound on tumor cell proliferation and survival. Our results showed that apoptosis induced by kahweol was associated with characteristic morphological changes, such as membrane blebbing and chromatin condensation.

In our study, BTF3 was downregulated in kahweol-treated NSCLC cells. BTF3 activates the transcription of RNA polymerase II through physiologic binding to promoter regions such as the TATA and CAAT boxes $(34,35)$. BTF is also known to regulate cell cycle arrest and apoptosis $(17,22,23)$. Recent research has shown that BTF3 is associated with the apoptotic pathway related to DNA damage (36). DNA damage leads to apoptosis through the activation of ATM in mitochondria and MAPK (mitogen-activated protein kinase) through phosphorylation (37).

Moreover, we found that kahweol-induced apoptosis occurred via inactivation of the ERK pathway. The ERK1/2 pathway is known to be associated with various cellular processes, including differentiation, transformation, proliferation, and apoptosis (38-40). In previous studies, several antiproliferative agents such as fucoidan, cucurbitacin B and apicidin, is able to inactivate the ERK1/2 pathway for apoptosis (41-43). In our study, we found that inactivation of ERK1/2 pathway is involved in kahweol-mediated apoptosis, as suggested by the use of PD98059, an inhibitor of the activation of MEK as a result of ERK pathway inhibition by kawheol (44).

To further characterize the effects of kahweol on BTF3, we also analyzed its effects on p27 p21, cyclin D1, and survivin. The cell cycle plays an important role in cell survival, growth, and proliferation (45) and involves several regulatory proteins between DNA synthesis and mitosis (45) that are closely associated with complexes containing cyclins and cyclindependent kinases (46). The G1 stage of the cell cycle, which precedes DNA synthesis, involves the p21 family (e.g., p21 and p27) which inhibits proliferation and DNA repair $(45,47,48)$. Cyclin D1 regulates the G1 restriction point (49). Survivin inhibits apoptosis (in the cytosol) and controls cell division (in the nucleus) (50). In addition, kahweol both induced Bax and reduced $\mathrm{Bcl}-2$ and $\mathrm{Bcl}-\mathrm{xL}$ expression while also activating caspase-3 and PARP, which suggests that kahweol suppressed BTF3 expression and ultimately led to apoptotic cell death. To the best of our knowledge, ours is the first report to demonstrate a potential role for kahweol in cancer chemoprevention, as shown in NSCLC cells. These results indicate that kahweol may inhibit cell proliferation and induce apoptosis due to BTF3 via the ERK signaling pathway. Thus, kahweol might 
be a promising chemotherapeutic agent in the treatment of patients with NSCLC.

\section{Acknowledgements}

This study was supported by a grant from the Next-Generation BioGreen 21 Program (project no. PJ01116401), Rural Development Administration, Republic of Korea.

\section{References}

1. Jemal A, Siegel R, Ward E, Murray T, Xu J and Thun MJ: Cancer statistics, 2007. CA Cancer J Clin 57: 43-66, 2007.

2. Siegel R, Ma J, Zou Z and Jemal A: Cancer statistics, 2014. CA Cancer J Clin 64: 9-29, 2014.

3. Wang L, Xiong Y, Sun Y, Fang Z, Li L, Ji H and Shi T: HLungDB: An integrated database of human lung cancer research. Nucleic Acids Res 38 (Database): D665-D669, 2010.

4. Hecht SS: Tobacco smoke carcinogens and lung cancer. J Natl Cancer Inst 91: 1194-1210, 1999.

5. Saintigny P and Burger JA: Recent advances in non-small cell lung cancer biology and clinical management. Discov Med 13: 287-297, 2012

6. Spiller MA: The chemical components of coffee. Prog Clin Biol Res 158: 91-147, 1984.

7. Lee KA, Chae JI and Shim JH: Natural diterpenes from coffee, cafestol and kahweol induce apoptosis through regulation of specificity protein 1 expression in human malignant pleural mesothelioma. J Biomed Sci 19: 60, 2012.

8. Cárdenas C, Quesada AR and Medina MA: Insights on the antitumor effects of kahweol on human breast cancer: Decreased survival and increased production of reactive oxygen species and cytotoxicity. Biochem Biophys Res Commun 447: 452-458, 2014.

9. Chae JI, Jeon YJ and Shim JH: Anti-proliferative properties of kahweol in oral squamous cancer through the regulation specificity protein 1 . Phytother Res 28: 1879-1886, 2014.

10. Cárdenas C, Quesada AR and Medina MA: Anti-angiogenic and anti-inflammatory properties of kahweol, a coffee diterpene. PLoS One 6: e23407, 2011.

11. Huber WW, Prustomersky S, Delbanco E, Uhl M, Scharf G, Turesky RJ, Thier R and Schulte-Hermann R: Enhancement of the chemoprotective enzymes glucuronosyl transferase and glutathione transferase in specific organs of the rat by the coffee components kahweol and cafestol. Arch Toxicol 76: 209-217, 2002.

12. Kim JY, Jung KS and Jeong HG: Suppressive effects of the kahweol and cafestol on cyclooxygenase-2 expression in macrophages. FEBS Lett 569: 321-326, 2004.

13. Kim JY, Jung KS, Lee KJ, Na HK, Chun HK, Kho YH and Jeong HG: The coffee diterpene kahweol suppress the inducible nitric oxide synthase expression in macrophages. Cancer Lett 213: 147-154, 2004

14. Tao KS, Wang W, Wang L, Cao DY, Li YQ, Wu SX and Dou KF: The multifaceted mechanisms for coffee's anti-tumorigenic effect on liver. Med Hypotheses 71: 730-736, 2008.

15. Kusumawidjaja G, Kayed H, Giese N, Bauer A, Erkan M, Giese T, Hoheise JD, Friess $\mathrm{H}$ and Kleeff J: Basic transcription factor 3 (BTF3) regulates transcription of tumor-associated genes in pancreatic cancer cells. Cancer Biol Ther 6: 367-376, 2007.

16. Deng JM and Behringer RR: An insertional mutation in the BTF3 transcription factor gene leads to an early postimplantation lethality in mice. Transgenic Res 4: 264-269, 1995.

17. Brockstedt E, Otto A, Rickers A, Bommert K and WittmannLiebold B: Preparative high-resolution two-dimensional electrophoresis enables the identification of RNA polymerase B transcription factor 3 as an apoptosis-associated protein in the human BL60-2 Burkitt lymphoma cell line. J Protein Chem 18 : 225-231, 1999.

18. Dunican DS, McWilliam P, Tighe O, Parle-McDermott A and Croke DT: Gene expression differences between the microsatellite instability (MIN) and chromosomal instability (CIN) phenotypes in colorectal cancer revealed by high-density cDNA array hybridization. Oncogene 21: 3253-3257, 2002.

19. Odreman F, Vindigni M, Gonzales ML, Niccolini B, Candiano G, Zanotti B, Skrap M, Pizzolitto S, Stanta G and Vindigni A: Proteomic studies on low- and high-grade human brain astrocytomas. J Proteome Res 4: 698-708, 2005.
20. Roy L, Laboissière S, Abdou E, Thibault G, Hamel N, Taheri M, Boismenu D, Lanoix J, Kearney RE and Paiement J: Proteomic analysis of the transitional endoplasmic reticulum in hepatocellular carcinoma: An organelle perspective on cancer. Biochim Biophys Acta 1804: 1869-1881, 2010.

21. Saraste A and Pulkki K: Morphologic and biochemical hallmarks of apoptosis. Cardiovasc Res 45: 528-537, 2000.

22. Bloss TA, Witze ES and Rothman JH: Suppression of CED-3-independent apoptosis by mitochondrial betaNAC in Caenorhabditis elegans. Nature 424: 1066-1071, 2003.

23. Thiede B, Dimmler C, Siejak F and Rudel T: Predominant identification of RNA-binding proteins in Fas-induced apoptosis by proteome analysis. J Biol Chem 276: 26044-26050, 2001.

24. Pearson G, Robinson F, Beers Gibson T, Xu BE, Karandikar M, Berman K and Cobb MH: Mitogen-activated protein (MAP) kinase pathways: Regulation and physiological functions. Endocr Rev 22: 153-183, 2001.

25. Persons DL, Yazlovitskaya EM and Pelling JC: Effect of extracellular signal-regulated kinase on p53 accumulation in response to cisplatin. J Biol Chem 275: 35778-35785, 2000.

26. Kris-Etherton PM, Hecker KD, Bonanome A, Coval SM, Binkoski AE, Hilpert KF, Griel AE and Etherton TD: Bioactive compounds in foods: Their role in the prevention of cardiovascular disease and cancer. Am J Med 113 (Suppl 9B): S71-S88, 2002.

27. Kim HG, Hwang YP and Jeong HG: Kahweol blocks STAT3 phosphorylation and induces apoptosis in human lung adenocarcinoma A549 cells. Toxicol Lett 187: 28-34, 2009.

28. Oh JH, Lee JT, Yang ES, Chang JS, Lee DS, Kim SH, Choi YH, Park JW and Kwon TK: The coffee diterpene kahweol induces apoptosis in human leukemia U937 cells through down-regulation of Akt phosphorylation and activation of JNK. Apoptosis 14: 1378-1386, 2009.

29. Weusten-Van der Wouw MP, Katan MB, Viani R, Huggett AC, Liardon R, Liardon R, Lund-Larsen PG, Thelle DS, Ahola I, Aro A, et al: Identity of the cholesterol-raising factor from boiled coffee and its effects on liver function enzymes. J Lipid Res 35: 721-733, 1994.

30. Ratnayake WM, Pelletier G, Hollywood R, Malcolm S and Stavric B: Investigation of the effect of coffee lipids on serum cholesterol in hamsters. Food Chem Toxicol 33: 195-201, 1995.

31. Schilter B, Perrin I, Cavin C and Huggett AC: Placental glutathione S-transferase (GST-P) induction as a potential mechanism for the anti-carcinogenic effect of the coffeespecific components cafestol and kahweol. Carcinogenesis 17: 2377-2384, 1996.

32. Hammons GJ, Fletcher JV, Stepps KR, Smith EA, Balentine DA, Harbowy ME and Kadlubar FF: Effects of chemoprotective agents on the metabolic activation of the carcinogenic arylamines PhIP and 4-aminobiphenyl in human and rat liver microsomes. Nutr Cancer 33: 46-52, 1999.

33. Miller EG, Formby WA, Rivera-Hidalgo F and Wright JM: Inhibition of hamster buccal pouch carcinogenesis by green coffee beans. Oral Surg Oral Med Oral Pathol 65: 745-749, 1988.

34. Cavallini B, Huet J, Plassat JL, Sentenac A, Egly JM and Chambon P: A yeast activity can substitute for the HeLa cell TATA box factor. Nature 334: 77-80, 1988

35. Zheng XM, Black D, Chambon P and Egly JM: Sequencing and expression of complementary DNA for the general transcription factor BTF3. Nature 344: 556-559, 1990.

36. Kastan MB and Lim DS: The many substrates and functions of ATM. Nat Rev Mol Cell Biol 1: 179-186, 2000.

37. Powers SK, Kavazis AN and McClung JM: Oxidative stress and disuse muscle atrophy. J Appl Physiol 102: 2389-2397, 2007.

38. Wada T and Penninger JM: Mitogen-activated protein kinases in apoptosis regulation. Oncogene 23: 2838-2849, 2004.

39. Tibbles LA and Woodgett JR: The stress-activated protein kinase pathways. Cell Mol Life Sci 55: 1230-1254, 1999.

40. Zhang W and Liu HT: MAPK signal pathways in the regulation of cell proliferation in mammalian cells. Cell Res 12: 9-18, 2002.

41. Ahn MY, Ahn JW, Kim HS, Lee J and Yoon JH: Apicidin inhibits cell growth by downregulating IGF-1R in salivary mucoepidermoid carcinoma cells. Oncol Rep 33: 1899-1907, 2015.

42. Hyun JH, Kim SC, Kang JI, Kim MK, Boo HJ, Kwon JM, Koh YS, Hyun JW, Park DB, Yoo ES, et al: Apoptosis inducing activity of fucoidan in HCT-15 colon carcinoma cells. Biol Pharm Bull 32: 1760-1764, 2009 
43. Zheng Q, Liu Y, Liu W, Ma F, Zhou Y, Chen M, Chang J, Wang Y, Yang $\mathrm{G}$ and $\mathrm{He} \mathrm{G}$ : Cucurbitacin $\mathrm{B}$ inhibits growth and induces apoptosis through the JAK2/STAT3 and MAPK pathways in SH-SY5Y human neuroblastoma cells. Mol Med Rep 10: 89-94, 2014.

44. Sheng Z, Knowlton K, Chen J, Hoshijima M, Brown JH and Chien KR: Cardiotrophin 1 (CT-1) inhibition of cardiac myocyte apoptosis via a mitogen-activated protein kinase-dependent pathway. Divergence from downstream CT-1 signals for myocardial cell hypertrophy. J Biol Chem 272: 5783-5791, 1997.

45. Schafer KA: The cell cycle: A review. Vet Pathol 35: 461-478, 1998.

46. Pines J: Cyclins and cyclin-dependent kinases: Theme and variations. Adv Cancer Res 66: 181-212, 1995.
47. Deng C, Zhang P, Harper JW, Elledge SJ and Leder P: Mice lacking p21CIP1/WAF1 undergo normal development, but are defective in G1 checkpoint control. Cell 82: 675-684, 1995.

48. Pan ZQ, Reardon JT, Li L, Flores-Rozas H, Legerski R, Sancar A and Hurwitz J: Inhibition of nucleotide excision repair by the cyclin-dependent kinase inhibitor p21. J Biol Chem 270: 22008-22016, 1995.

49. Yasutis KM and Kozminski KG: Cell cycle checkpoint regulators reach a zillion. Cell Cycle 12: 1501-1509, 2013.

50. Khan S, Ferguson Bennit H, Asuncion Valenzuela MM, Turay D, Diaz Osterman CJ, Moyron RB, Esebanmen GE, Ashok A and Wall NR: Localization and upregulation of survivin in cancer health disparities: A clinical perspective. Biologics 9: 57-67, 2015. 